\title{
PENGARUH PIJAT STIMULUS OKSITOSIN TERHADAP LET DOWN REFLEK PADA IBU POSTPARTUM DI BPM MUADDAH, S.Sit DESA MEUNASAH GADONG KECAMATAN KOTA JUANG KABUPATEN BIREUEN
}

\author{
The Effect Of Oxytocin Stimulus Massage On Let Down Reflex In \\ Postpartum Mothers In BPM Muaddah, S.Sit Meunasah Gadong Village \\ Kota Juang District Bireuen Regency
}

\author{
Sarah Nadiya ${ }^{* 1}$, Rahmah $^{* 2}$
}

\begin{abstract}
Dosen Akbid Munawarah, Jl. Sultan Iskandar Muda No. 18 Kota Juang, Bireuen 24251, Indonesia Mahasiswa Akbid Munawarah, Jl. Sultan Iskandar Muda No. 18 Kota Juang, Bireuen 24251, Indonesia

*Korespondensi Penulis : sarahnadiya@akbid.ac.id*1
\end{abstract}

\begin{abstract}
ABSTRAK
Latar Belakang : ASI dapat terhambat produksinya dengan adanya feedback inhibitor, yaitu suatu faktor lokal, bila saluran ASI penuh untuk mengirim impuls untuk mengurangi produksi. Cara mengatasinya yaitu dengan mengosongkan saluran secara teratur tanpa dijadwalkan, jika terasa sakit maka lakukan release atau pijat oksitosin. Tujuan : Untuk mengetahui ada pengaruh pijat stimulus oksitosin terhadap let down reflek pada ibu postpartum Metode : Penelitian yang digunakan adalah preeksperimental design dengan pendekatan one group pretest posttest. Populasi dalam penelitian ini adalah seluruh ibu postpartum di BPM Muaddah, S.SiT Desa Meunasah Gadong Kecamatan Kota Juang Kabupaten Bireuen. Tehnik pengambilan sampel yaitu dengan cara accidental sampling sebanyak 39 orang. Data dianalisis statistic menggunakan uji wilxocon. Hasil : Berdasarkan hasil penelitian maka diperoleh hasil data disajikan dalam bentuk table distribusi frekuensi berdasarkan indikasi dilakukannya, dapat disimpulkan bahwa hasil analisis statistic menggunakan uji wilxocon, didapatkan nilai p value $(0,000)<\alpha(0,05)$ maka Ha diterima dan Ho ditolak. Kesimpulan : Dengan demikian dapat disimpulkan bahwa ada pengaruh pijat stimulus oksitosin terhadap let down reflex pada ibu nifas.
\end{abstract}

\section{Kata kunci : Pijat Stimulus Oksitosin, Let Down Refleks}

\section{ABSTRACT}

Background: Breast milk production can be hampered by the presence of feedback inhibitors, which are a local factor, when the milk ducts are full to send impulses to reduce production. The fix is to empty the channel regularly without a schedule, if it hurts then do an oxytocin release or massage. Objective: This study was conducted to determine the effect of oxytocin stimulus massage on let down reflex in postpartum mothers. Method: The research design was used pre-experimental design with one group pretest posttest approach. The population in this study were all postpartum mothers in BPM Muaddah, S.SiT, Meunasah Gadong Village, Kota Juang District, Bireuen Regency. The sampling technique was by accidental sampling as many as 39 people. Results: Based on the results of the study with the chi square 
Journal of Healthcare Technology and Medicine Vol. 6 No. 2 Oktober 2020

Universitas Ubudiyah Indonesia

e-ISSN : 2615-109X

statistical test, it was found that there was a relationship between exclusive breastfeeding and the development of children under five with a $p$ value (0.005) $<\alpha(0.05)$. And there is a relationship between psychosocial stimulation and the development of toddlers with $p$ value (0.031) $<\alpha$ (0.05). Conclusion: This research is expected for respondents to be more active in seeking information and gain insight from the media or health workers on how to stimulate a reflex let down

Keywords $\quad$ : Exclusive Breastfeeding, Psychosocial Stimulation, Toddler Development

\section{PENDAHULUAN}

Pemberian Air Susu Ibu (ASI) sebagai salah satu yang memberikan pengaruh paling besar terhadap kelangsungan hidup anak, pertumbuhan, dan perkembangannya. Banyak dijumpai para ibu melakukan perawatan nifas berdasarkan budaya dan tradisi, termasuk dalam hal menyusui, namun pada sebagian ibu mungkin saja terjadi kesulitan pengeluaran ASI karena lebih banyak ibu terpengaruh mitos sehingga ibu tidak yakin bisa memberikan ASI pada bayi. Perasaan ibu yang tidak yakin bisa memberikan ASI pada bayi akan menyebabkan penurunan hormone oksitosin sehingga ASI tidak dapat keluar segera setelah melahirkan dan akhirnya ibu memutuskan untuk memberikan susu formula. Hal ini disebabkan karena ibu tidak memproduksi ASI dalam jumlah yang cukup untuk bayi (Astutik, 2014).

Menurut data dari Demographic and Health Survey World Health Organization (WHO, pemberian ASI secara dini selama 4 bulan pertama sangat rendah yaitu $15 \%$. Oleh karena itu WHO menganjurkan agar melakukan Inisiasi Menyusu Dini (IMD) sehingga bayi mendapatkan kolostrum yang terdapat dalam ASI ibu yang pertama keluar sehingga dapat mencegah $22 \%$ resiko kematian pada bayi baru lahir. Sedangkan bayi yang diberikan ASI Eksklusif selama 4 bulan dapat menurunkan angka kematian dan kesakitan pada bayi (Astuti, 2009). Berdasarkan survei dari World Health Organization (WHO) terhadap lebih dari 3000 ibu pasca persalinan di beberapa negara, menunjukkan bahwa ibu yang melakukan IMD atau pemberian ASI minimal satu jam setelah bayi lahir hanya sekitar 38,33\%. Cakupan IMD di Indonesia masih rendah yaitu 29,3\% ditahun 2010 mengalami kenaikan menjadi $34,5 \%$ di tahun 2013 (Kemenkes RI, 2013).

Pemberian ASI yang direkomendasikan adalah segera (30 menitsampai 1 jam) setelah melahirkan, dilanjutkan dengan pemberian ASI Eksklusif hingga usia 6 bulan dan pemberian makanan pendamping ASI (MP-ASI) setelah usia 6 bulan serta tetap melanjutkan pemberian ASI sampai umur 2 tahun. Ibu yang memberi ASI dalam 1 jam pertama setelah bersalin berpeluang 2 sampai 8 kali dapat memberikan ASI selanjutnya dan hampir 77\% akan berhasil 
Journal of Healthcare Technology and Medicine Vol. 6 No. 2 Oktober 2020

Universitas Ubudiyah Indonesia

e-ISSN : 2615-109X

menyusui bayinya. Bayi yang tidak mendapatkan ASI secara menyusui dini atau Ibu menyusui diatas 24 jam akan beresiko 2-3 kali meninggal dibandingkan dengan bayi yang disusui dalam 1 jam pertama (Depkes RI, 2010).

Menurut hasil Riset Kesehatan Dasar Indonesia (RISKESDAS) pada tahun 2018, tidak ada data khusus mengenai pemberian kolostrum. Namun patokan keberhasilan pemberian kolostrum dapat kita lihat dari data proporsi Inisiasi Menyusu Dini (IMD) pada bayi 0-23 bulan dari seluruh provinsi yang ada di Indonesia yaitu sebesar 58,2\%. Sedangkan di Provinsi Aceh, keberhasilan pemberian kolostrum dapat kita lihat dari data proporsi Inisiasi Menyusu Dini (IMD) pada bayi 0-23 bulan sebesar 40\% dari total bayi yang lahir seluruh provinsi Aceh (RISKESDAS, 2018).

ASI merupakan cairan kehidupan terbaik yang sangat penting dibutuhkan oleh bayi. ASI mengandung berbagai zat yang penting untuk tumbuh kembang bayi dan sesuai kebutuhannya. Banyak hal yang memengaruhi produksi ASI, yaiu hormon prolaktin dan oksitosin. Prolaktin mempengaruhi jumlah produksi ASI sedangkan oksitosin mempengaruhi proses pengeluaran ASI. Untuk mengeluarkan ASI diperlukan hormon oksitosin yang kerjanya dipengaruhi oleh isapan bayi. Semakin dihisap semakin banyak pula ASI yang keluar. Hormon oksitosin sering disebut hormon kasih sayang karena sering berhubungan dengan suasana hati, rasa bahagia, rasa dicintai, rasa aman, ketenangan dan rileks (Yanti, 2011)

Permasalahan kurangnya rangsangan hormon prolaktin dan oksitosin yang sangat berperan dalam kelancaran produksi ASI. Hal ini dapat dapat mempengaruhi pengeluaran ASI memberikan dampak buruk untuk kehidupan bayi dikarenakan nilai gizi pada ASI lebih tinggi dibandingkan dengan susu formula, akan tetapi penggunaan susu formula merupakan alternatif yang dianggap paling tepat untuk mengganti produksi ASI yang menurun.Salah satu upaya yang dapat dilakukan ibu dan keluarga, untuk meningkatkan produksi ASI diperlukan hormon oksitosin. Pada ibu setelah melahirkan dapat melakukan pijat oksitosin. Pijat oksitosin merupakan pemijatan sepanjang tulang belakang (tulang vertebrae sampai tulang coste kelima-enam). Pijat oksitosin dilakukan pada ibu postpartum dengan durasi 3 menit dan frekuensi pemberian pijatan 2 kali sehari. Pijat ini tidak harus dilakukan oleh petugas kesehatan tetapi dapat dilakukan oleh suami atau keluarga yang lain. Mekanisme kerja dalam pelaksanaan pijat oksitosin merangsang saraf dikirim keotak sehingga hormon oksitosin dapat 
Journal of Healthcare Technology and Medicine Vol. 6 No. 2 Oktober 2020

Universitas Ubudiyah Indonesia

e-ISSN : 2615-109X

dikeluarkan dan mengalir kedalam darah kemudian masuk ke payudara dan menyebabkan otot-otot sekitar alveoli berkontraksi dan membuat ASI mengalir (Bobak, 2005).

ASI dapat terhambat produksinya dengan adanya feedback inhibitor, yaitu suatu faktor lokal, bila saluran ASI penuh untuk mengirim impuls untuk mengurangi produksi. Cara mengatasi nya yaitu dengan mengosongkan saluran secara teratur tanpa dijadwalkan, jika terasa sakit maka lakukan release atau pijat oksitosin (Rukiyah, 2012).

Dalam pembentukan ASI, ada dua refleks yang mebantu yaitu reflek let down dan refleks prolaktin. Refleks let downreflek merupakan refleks dengan dibentuknya hormon prolaktin rangsangan yang berasal dari isapan bayi akan dilanjutkan ke neurohipofise yang kemdian dikeluarkan oksitosin melalui aliran darah, hormon ini akan menuju uterus yang menimbulkan kontraksi pada uetrus sehinga terjadi involusi dari organ tersebut. Oksitosin yang sampai pada alveoli akan mempengaruhi sel mioepitelium. Kontraksi sel akan memeras ASI yang telah terbuat keluar alveolidan sistem masuk ke duktus laktiferus masuk ke mulut bayi (Rukiyah, 2012).

Refleks let down sangat dipengaruhi oleh psikologis ibu seperti memikirkan bayi, mencium, melihat bayi dan mendengarkan suara bayi. Sedangkan faktor yang menghambat adalah perasaan stress, gelisah, kurang percaya diri, takut, nyeri dan cemas. Tanda refleks let down baik adalah adanya tetesan air susu dari payudara sebelum bayi mulai memperoleh susu dari payudara ibunya dimana air susu menetes walaupun tidak dalam keadaan bayi menyusu. Agar refleks let down terjadi dengan baik maka perlu dilakukan stimulasi pengeluaran hormon oksitosin yaitu dengan merangsang titik di atas putting, titik tepat pada putting dan titik di bawah puting serta titik di punggung yang segaris dengan payudara. Salah satu cara merangsang stimulasi pengeluaran oksitosin adalah dengan melakukan pemijatan yang dapat juga meningkatkan rasa nyaman terhadap ibu (Ariani 2010).

Berdasarkan data yang diperoleh dari Dinas kesehatan Kabupaten Bireuen, jumlah bayi yang mendapatkan IMD sebanyak 6.690 jiwa (78,2\%), dengan Wilayah Kerja terbanyak yaitu Wilayah Kerja Puskesmas Kota Juang sebanyak 864 jiwa (97,3\%).

Berdasarkan data yang diperoleh dari BPM Muaddah, S.SiT Desa Meunasah gadong Kecamatan Kota Juang Kabupaten Bireuen pada tahun 2019, jumlah bayi lahir sebanyak 312 orang dan menurut data semua diterapkan IMD (Inisiasi Menyusui Dini). Berdasarkan hasil survey awal yang peneliti lakukan ke 10 ibu nifas, mereka mengatakan setelah bayi mereka lahir bayi diletakkan diatas dada ibu untuk menyusu sendiri bayinya. Dari 10 orang ibu nifas 
Journal of Healthcare Technology and Medicine Vol. 6 No. 2 Oktober 2020

Universitas Ubudiyah Indonesia

e-ISSN : 2615-109X

yang diwawancarai, 6 dari mereka mengatakan ASI tidak keluar, bidan membantu mengurut punggung serta payudara dan memberikan beberapa penyuluhan kepada ibu agar tetap menyusui hingga ASI lancar. Dari hasil pemijatan, dari 6 ibu yang ASI nya tidak keluar, 4 dari mereka sudah mengalami refleks let down yang aktif.

Berdasarkan latar belakang diatas, maka peneliti tertarik untuk meneliti tentang "Pengaruh pijat stimulus oksitosin terhadap let down reflek pada ibu post partum di BPM Muaddah, S.SiT Desa Meunasah Gadong Kecamatan Kota Juang Kabupaten Bireuen”.

\section{METODE PENELITIAN}

Desain penelitian yang digunakan adalah preeksperimental design dengan pendekatan one group pretest posttest yaitu rancangan penelitian yang dilakukan dengan cara memberikan pretest (pengamatan awal) telebih dahulu sebelum diberikan intervensi. Setelah diberikan intervensi, kemudian dilakukan posttest (pengamatan akhir) (Hidayat, 2014). Bentuk rancangan penelitian ini adalah sebagai berikut (Notoatmodjo, 2012).

Pretest Perlakuan Posttest

\begin{tabular}{|ll|}
\hline 01 & $\mathrm{X}$ \\
\hline
\end{tabular}

Gambar 3.1. Rancangan One Group Pretest Posttest

Penelitian dilaksanakan di BPM Muaddah, S.Sit di Desa Meunasah Gadong Kecamatan Kota Juang Kabupaten Bireuen. Waktu penelitian dilaksanakan pada bulan Agustus 2020. Populasi dalam penelitian ini adalah seluruh ibu postpartum di BPM Muaddah S.SiT Desa Meunasah Gadong Kecamatan Kota Juang Kabupaten Bireuen sebanyak 39 orang. Tehnik pengambilan sampel yaitu dengan cara accidental sampling.

\section{HASIL PENELITIAN}

Analisis Univariat : Berdasarkan tabel 1 dapat dilihat bahwa mayoritas responden mengalami let down reflex yang kurang aktif sebelum dilakukan pijat stimulus oksitosin yaitu sebanyak 27 responden $(69 \%)$.

Tabel 1. Distribusi Frekuensi Responden Berdasarkan Let Down Reflex Sebelum Pijat Oksitosin di BPM Muaddah, S.SiT Desa Meunasah Gadong Kecamatan Kota Juang Kabupaten Bireuen 


\begin{tabular}{cccc}
\hline \multirow{2}{*}{ No } & Let Down Refleks & \multicolumn{2}{c}{ Jumlah } \\
\cline { 3 - 4 } & & $\mathbf{f}$ & \% \\
\hline 1 & Aktif & 12 & 31 \\
2 & Kurangaktif & 27 & 69 \\
\hline & Total & $\mathbf{3 9}$ & $\mathbf{1 0 0}$ \\
\hline
\end{tabular}

Analisis Bivariat : Berdasarkan tabel di atas dapat diketahui bahwa N, mean rank dan sum of rank pada negatif rank yaitu 0 yang artinya tidak ada penurunan let down reflex dari sebelum atau sesudah dilakukan pijat stimulus oksitosin, Pada nilai positif rank menujukkan nilai $\mathrm{N}$ 18, nilai mean rank 9,50, sum of rank171,00yang artinya ada responden yang mengalami peningkatan let down reflex dari sebelum pemijatan stimulus oksitosin sampai sesudah pemijatan stimulus oksitosin. Sedangkan pada nilai $\mathrm{N}$ ties terdapat 21 responden yang artinya ada responden yang memiliki let down refleks yang sama yaitu sebelum pemijatan stimulus oksitosin dan sesudah dilakukan pemijatan stimulus oksitosin.

Berdasarkan analisis statistik menggunakan uji wilxocon (melihat perbandingan), didapatkan nilai p value $(0,000)<\alpha(0,05)$ maka Ha diterima dan Ho ditolak. Dengan demikian dapat disimpulkan bahwa ada pengaruh pijat stimulus oksitosin terhadap let down reflek pada ibu nifas.

\section{TABEL 4.4}

Pengaruh Pijat Stimulus OksitosinTerhadap Let Down Refleks Pada Ibu Postpartum di BPM Muaddah, S.SiT Desa Meunasah Gadong Kecamatan Kota Juang Kabupaten Bireuen

\begin{tabular}{|c|c|c|c|c|c|c|c|c|}
\hline Variabel & Intervensi & & $\mathbf{N}$ & $\begin{array}{l}\text { Mean } \\
\text { Rank }\end{array}$ & $\begin{array}{c}\text { Sum } \\
\text { of } \\
\text { Rank }\end{array}$ & $Z$ & $\begin{array}{c}P \\
\text { val } \\
\text { ue }\end{array}$ & $\alpha$ \\
\hline \multirow{4}{*}{$\begin{array}{l}\text { Letdown } \\
\text { Refleks }\end{array}$} & Sebelum- & Negatif & $0^{\mathrm{a}}$ & ,00 & ,00 & \multirow{4}{*}{$-4.234^{\mathrm{a}}$} & \multirow{4}{*}{0,000} & \multirow{4}{*}{0,05} \\
\hline & \multirow{3}{*}{ Sesudah } & Rank & & & & & & \\
\hline & & Positif & & & & & & \\
\hline & & Rank & $18^{\mathrm{b}}$ & 9,50 & 171,00 & & & \\
\hline
\end{tabular}


Journal of Healthcare Technology and Medicine Vol. 6 No. 2 Oktober 2020

Universitas Ubudiyah Indonesia

e-ISSN : 2615-109X

Ties $\quad 21^{\mathrm{c}}$

Jumlah 39

\section{PEMBAHASAN}

Berdasarkan hasil uji Wilcoxon, diketahui bahwa N, mean rank dan sum of rank pada negatif rank yaitu 0 yang artinya tidak ada penurunan let down reflex dari sebelum atau sesudah dilakukan pijat stimulus oksitosin, Pada nilai positif rank menujukkan nilai N 18, nilai mean rank 9,50, sum of rank 171,00 yang artinya ada responden yang mengalami peningkatan let down reflex dari sebelum pemijatan stimulus oksitosin sampai sesudah pemijatan stimulus oksitosin. Sedangkan pada nilai $\mathrm{N}$ ties terdapat 21 responden yang artinya ada responden yang memiliki let down refleks yang sama yaitu sebelum pemijatan stimulus oksitosin dan sesudah dilakukan pemijatan stimulus oksitosin.

Berdasarkan analisis statistik menggunakan uji wilxocon, didapatkan nilai $\mathrm{p}$ value $(0,000)<\alpha(0,05)$ maka Ha diterima dan Ho ditolak. Dengan demikian dapat disimpulkan bahwa ada pengaruh pijat stimulus oksitosin terhadap let down reflek pada ibu nifas.

Hormon oksitosin berada di dalam hipotolamus pada otak. Hormon tersebut dikeluarkan oleh kelenjar pituitari yang terletak di dasar otak. Menurut penelitian Morhenn, 2012 hubungan pemijatan otot tulang belakang dengan peningkatan kadar oksitosin dan menurunkan kadar adrenocorticotropin hormon (ACTH), Nitric Oxide (NO) dan BetaEndorphin (BE). Perbandingan efek pemijatan pada kelompok intervensi dan kelompok kontrol mempunyai perbedaan yang signifikan $\mathrm{p}<0,05$. Peran oksitosin dalam berbagai tingkah laku manusia, seperti orgasme, kedekatan sosial, dan sikap keibuan. Untuk alasan ini, hormon oksitosin terkadang dianggap sebagai hormon cinta (Lestari, 2017).

Usia ibu sangat berpengaruh terhadap kelancara prosuksi ASI ibu. Usia ini adalah usia yang baik bagi wanita untuk hamil dan melahirkan. Hal ini disebakan karena secara fisik seluruh organ reproduksi dan hormon yang mendukung system reproduksi telah mengalami penurunan secara kuantitas dan kualitas. Maka disarankan wanita yang hamil dan melahirkan baiknya adalah berumur 20-35 tahun (Ambarwati, 2010 Dikutip dari Fajrin, 2015).

Penelitian dengan judul "Pengaruh Pijat Stimulasi Oksitosin Terhadap Let Down Reflek Pada Ibu Post Partum Di Rumah Bersalin Mardi Rahayu Kali banteng Semarang” menunjukkan sebelum dilakukan pijat stimulasi oksitosin sebagian besar memiliki LDR kurang aktif sebanyak 20 orang $(66,7 \%)$ dan LDR aktif sebanyak 10 orang (33,3\%). Setelah 
Journal of Healthcare Technology and Medicine Vol. 6 No. 2 Oktober 2020

Universitas Ubudiyah Indonesia

e-ISSN : 2615-109X

dilakukan pijat stimulasi oksitosin sebagian besar memiliki LDR aktif meningkat sebanyak 19 orang $(63,3 \%)$ dan LDR kurang aktif sebanyak 11 orang (36,7\%). Hasil uji wilcoxon didapatkan hasil $\mathrm{p}$ value $=0,00(<0,005)$ yang berarti bahwa hipotesis diterima yaitu terdapat pengaruh pijat stimulasi oksitosin terhadapo LDR pada ibu post partum di RB Mardi Rahayu Kalibanteng Semarang. Berdasarkan hasil penelitian diharapkan rumah bersalin yang menyediakan layanan persalinan diharapkan melakukan pijat stimulasi oksitosin terhadap ibu post partum mulai hari pertama persalinan agar refleks let down menjadi lebih aktif sehingga produksi ASI meningkat (Fajrin, 2015).

Asumsi peneliti, adanya pengaruh pijat stimulus oksitosin terhadap let down reflex pada ibu nifas, dikarenakan banyak dari ibu yang awalnya mengalami let down reflex yang kurang aktif sebelum dilakukan pemijatan stimulus oksitosin. Hal ini dipengaruhi oleh riwayat paritas ibu yang mayoritas merupakan ibu primipara dengan usia ibu yang masih ratarata dalam kategori tidak resiko tinggi (antara 20 sampai 35 tahun). Setelah dilakukan pemijatan stimulus oksitosin, banyak dari responden yang mengalami perubahan let down reflex sehingga pengeluaran air susu ibu lancar. Selain itu bidan dan peneliti juga memberikan edukasi saa tmelakukan pemijatan sehingga menyebabkan ibu menjadi rileks sehingga menimbulkan let down reflex yang baik dan aktif.

\section{KESIMPULAN}

Berdasarkan hasil penelitian maka dapat disimpulkan sebagai berikut: Dengan demikian dapat disimpulkan bahwa ada pengaruh pijat stimulus oksitosin terhadap let down reflex pada ibu nifas di BPM Muaddah, S.Sit di desa Meunasah Gadong Kecamatan Kota Juang Kabupaten Bireuen.

\section{SARAN}

Diharapkan kepada responden untuk lebih aktif mencari informasi dan menambah wawasan dari media atau tenaga kesehatan mengenai cara merangsang agar terjadi reflex let down dan diharapkan kepada pemberi pelayanan kesehatan khususnya bidan di Wilayah Kabupaten Bireuen lebih aktif lagi dalam memberikan bimbingan dan informasi kepada pasien tentang perawatan payudara untuk meningkatkan reflex let down menjadi lebih aktif ketika bayi lahir, sehingga volume ASI mejadi lebih banyak serta member pengaruh stimulus pijat oksitosin terhadap reflex let down. 
Journal of Healthcare Technology and Medicine Vol. 6 No. 2 Oktober 2020

Universitas Ubudiyah Indonesia

e-ISSN : 2615-109X

\section{DAFTAR PUSTAKA}

Ambarwati. (2009). Asuhan Kebidanan Nifas Cendika Pres. Yogjakarta.

Ariani. (2010). Ibu Susui Aku. Khazanah Intelektual: Jakarta.

Astutik. (2014). Payudara dan Laktasi. Salemba Medika. Jakarta.

Astuti. (2009). Studi Deskriptif Tingkat Pengetahuan Ibu Menyusui Tentang ASI Ekslusif di Puskesmas Cilacap Utara. Kesehatan Masyarakat. Vol 3.Diakses

Biancuzzo. (2003). Breastfeeding The Newborn. Clinical Stategies For Nurses, Mosby, St. Louis.

Bobak. (2005). Buku Ajar Keperawatan Maternitas. Edisi 4. EGC. Jakarta.

Depkes RI (2012). Pemberian ASI Dalam Usaha Persalinan Normal. Depkes. Jakarta.

_ 2010. ManajemenLaktasi, Buku Panduan BagiBidan dan PetugasKesehatan. Depkes. Jakarta.

Fajrin, 2015. Pengaruh Pijat Stimulasi Oksitosin Terhadap Let Down Reflek Pada Ibu Post Partum Di Rumah Bersalin Mardi Rahayu Kalibanteng Semarang. http://www.Jurnal Keperawatan Maternitas. htm.

Hubertin, 2007. Konsep Penerapan ASI Ekslusif. EGC. Jakarta.

Iman, 2016. Panduan Penyusunan Karya Tulis Ilmiah Bidan Kesehatan. Cita Pusaka: Medan.

—. 2014. Pemanfaatan SPSS Dalam Penelitian Bidang Kesehatan \& Umum. Cita Pusaka: Medan.

Jannah. 2013. Asuhan Kebidanan Ibu Nifas. Ar-Ruzz Media: Yogjakarta.

Kemenkes RI, 2013. RisetKesehatan Dasar Badan Penelitian dan PengembanganKesehatan 2013http://kemenkes.go.id. Diakses oleh Rahmah pada tanggal 16 Mei 2020 at 08.40 am.

(2012). Riset Kesehatan Dasar Badan Penelitian dan Pengembangan Kesehatan 2013http://kemenkes.go.id. Diakses oleh Rahmah pada tanggal 16 Mei 2020 at 08.40 am.

Nugroho, 2014. Buku Ajar AsuhanKebidanan 3 Nifas. NuhaMedika. Jogjakarta.

Proverawati. 2010. Kapita Selekta ASI \& Menyusui. Nuha Medika. Yogjakarta.

Rukiyah 2012. Asuhan Kebidanan III Nifas. Trans Info Media. Jakarta. 
Journal of Healthcare Technology and Medicine Vol. 6 No. 2 Oktober 2020

Universitas Ubudiyah Indonesia

e-ISSN : 2615-109X

Rosya 2016. Pengaruh Pijat Oksitosin Terhadap Peningkatan Produksi Asi Ibu Menyusui Di Puskesmas Plus Mandiangin. http://www.jurnalipteksterapan. htm.

Roesli. 2009. Inisiasi Menyusui Dini Plus ASI Ekslusif. Pustaka Bunda. Jakarta.

RISKESDAS, 2018. Riset Kesehatan Dasar Indonesia Tahun 2018. http//www.riskesdas.com. Diaksespada tanggal 20 April 2020.

Soleha. (2009). Asuhan Kebidanan Pada Masa Nifas Salemba Medika. Jakarta.

UNICEF,WHO/IDAI, 2013. Pemberian Makanan Pada Bayi. Jakarta.

Wiji. 2012. ASI dan Pedoman Ibu Menyusui. Nuha Medika. Yogjakarta.

Yanti. 2011. Asuhan Kebidanan Masa Nifas. Refika Aditama. Bandung. 